\title{
Classifying the Nature of Reflective Writing During Periods of Professional Experience
}

Andrew Roberts: Cardiff University, UK

\begin{abstract}
Many authors have highlighted the importance of reflection in helping students to learn from their experiences, particularly in the field of professional development. Nevertheless many students struggle, at least initially, to engage fully with high levels of what might be described as critical reflection, that might lead to a transformation in an individual's perspective. Individual differences amongst students suggest that some are more inclined towards reflective practice than others. Previous research has suggested that students' propensity to reflect may impact upon the level and focus of their reflection.

This study aims to classify the different approaches to writing in students' portfolios, particularly in terms of how they focus their reflection - whether in terms of what the student is achieving, or the process that they are undertaking.

The research focuses on the portfolios submitted by a cohort of architectural students undertaking their first experience of architectural practice. However it is anticipated that the findings may apply to a range of professions.

The study has led to the generation of a rubric by which student work can be assessed. This will enable future research to determine the extent to which an individual's propensity to reflect might impact on the nature of what students write.
\end{abstract}

Keywords: Reflection, Learning Styles, Professional Experience, Assessment 
A. Roberts: Classifying the Nature of Reflective Writing During Periods of Professional Experience

\section{Context}

Many authors have highlighted the importance of reflection in helping students to learn from their experiences, particularly in the field of professional development (Boud et al.,1985; Mezirow, 1991; Moon, 1999). It is commonly recognised that engaging in high levels of reflection can have benefits in terms of the learning achieved. It is argued that reflection facilitates the linking of theory and practice, and encourages critical evaluation (Bain et al., 1999; Calderhead, 1988). Reflection also provides the link between an experience and learning from that experience (Blackwell et al., 2001), providing meaning to something that is personal and subjective (Platzer et al., 1997, p.104).

One of the difficulties inherent within the literature on reflection, is that there is little consensus about what is meant by reflection, with individual authors adopting definitions to suit their particular avenue of investigation or their discipline. McCarthy (2011) argues that this is a result of the fact that reflection is a socially constructed term which is inevitably subject to personal interpretation. Some see reflection as a particular form of problem solving (Dewey, 1933; Schön, 1983), whilst others see it more of a means to reach levels of personal emancipation (Habermas, 1987; Mezirow, 1991). Reflection can also be seen as taking an overview, reviewing one's practice, making connections, a form of critical thinking, a sign of wisdom, or considered thought. Others consider reflection to be a polar opposite of impulsivity (Kagan et al., 1964). In his cycle of experiential learning Kolb (1984) sees reflection as the opposite of action, whereas Schon (1983) believes that reflection and action are closely bound together. Moon takes the view that although these may appear to be very different, the underpinning mental processes are the same.

...the common usage of the word [reflection] imply a form of mental processing with a purpose and/or an anticipated outcome that is applied to relatively complicated or unstructured ideas for which there is not an obvious solution. This suggests close association with learning and the representation of learning.

(Moon, 1999, p.4)

Moon's view is that within this definition, reflection can take a variety of forms depending upon the goals that are set and the frameworks or scaffolding that is put in place.

A number of researchers have attempted to classify the different types of reflection that might appear in reflective writing. These have commonly focussed on measuring the level of reflection provided, using taxonomies that outline the levels of cognitive sophistication (Hatton and Smith, 1995). Hatton and Smith's own taxonomy ranges from non-reflective Descriptive Writing, through basic Descriptive Reflection, which contains a degree of reasoned justification or explanation on what had been described. Next, Dialogic Reflection is more analytical, suggesting a 'stepping back' from the situation and providing a reasoned argument from a range of perspectives. Finally Critical Reflection makes use of a broad range of perspectives and contexts in order to evaluate the circumstances described.

Classifications based on levels of reflection however, ignore differences in the nature of reflection undertaken. A more sophisticated model might also recognise that when reflecting there can be variation in the subject that is reflected on. Mezirow (1991), with particular 
reference to reflection as a means of creative problem solving, makes the distinction between reflection on content and reflection on process. Content reflection refers to an examination of the content or description of a problem (the what), whereas process reflection examines the process by which a problem was addressed (the how). Mezirow identifies a third category of reflection - premise reflection, which questions the beliefs and values that underpin a particular situation. He argues that it is only this type of reflection that can lead to a transformation in perspective. Kember et al. (1999) suggest content and process reflection as being of equivalent cognitive level, whilst premise reflection is at a higher level. If content and process reflection are at the same level, this suggests that the focus of reflection and the level of reflection may represent separate dimensions, an idea suggested by LaBoskey (1993). Bain et al. (1999) conducted a study with pre-service teachers and identified four key foci of reflection: focus on teaching, focus on self, focus on professional issues and focus on students or class. They also proposed a five point scale by which levels of reflection could be measured, which is based loosely on Biggs' SOLO taxonomy (Biggs and Tang, 2007) but also on the taxonomy developed by Hatton and Smith (1995) referred to above. Their scale runs from a low level of reporting, through responding, relating, reasoning to a high level of reconstructing, where students demonstrate abstract thinking and draw original conclusions from their reflection.

Irrespective of definition, evidence suggests that many students struggle, at least initially, to engage fully with reflection, particularly at those higher cognitive levels that might lead to a transformation in an individual's perspective (Mezirow, 1991; Samuels and Betts, 2007). Individual differences amongst students suggest that some are more inclined towards reflective practice than others. LaBoskey (1993) for example, differentiates between those students who she refers to as 'Alert Novices', who seem inclined to adopt a reflective, questioning stance, and 'Common-Sense Thinkers', who base decision making on what appears obvious at the time. Roberts and Yoell (2009) also suggest that students might show different propensities to reflect and categorise them as 'Naturals' - who enjoy and appear to benefit from reflection, the 'Disengaged' who only engage with reflection if they are required to and struggle to see its benefits and 'Converts' who were previously disengaged but subsequently have become converted to the benefits of reflection. Grant et al. (2002) have conducted research into an individual's propensity towards 'Self Reflection' through the development of their questionnaire-based test, the Self Reflection and Insight Scale (SRIS). They similarly conclude that certain students are more naturally inclined to reflect than others. They do, however, use a narrower definition of reflection based around the evaluation of personal thoughts, feelings and values, so their findings may not hold true for all types of reflection. Cranton (2006, p.94) contrasts critical reflection with critical self-reflection, arguing that the latter is more likely to be demonstrated by those with an introverted personality. Irrespective of an individual's propensity to reflect, Bain et al. (1999) have shown that much student work which is intended to be reflective is little more than a description of their experience. Those responsible for running courses with a reflective component may need to provide the necessary support or scaffolding to help students raise their level of reflection (Samuels and Betts, 2007). 
A model proposed by Roberts (2009) developed from an earlier model by Smith and Tillema (2003) (Figure 1) attempts to illustrate the relationship between a student's individual propensity to reflect, the scaffolding provided by faculty and the nature of a student's eventual output in terms of what they write and the level of reflection demonstrated. The model is based around the development of a reflective portfolio, typically compiled by students who are undergoing some form of work placement. It supposes that students are provided with guidance as to the expected focus of the portfolio - whether that portfolio should have a product focus - related to the outcomes of students' work and their achievements, or a process focus, where students reflect on their learning processes required to make that achievement.

The vertical axis in Figure 1 represents the focus of reflection that the students perceive they are expected to adopt: product or process. This perception may be the result of explicit instructions from their tutor, or may be a result of the students' interpretation of guidance given. The horizontal axis represents a continuum between those students who are naturally reflective individuals (Reflectors) and those who are not (Recorders).

The model suggests that those who are not naturally inclined to reflect, when the perceived goal is to collect evidence of their achievements, are likely to generate a dossier of evidence, which might be characterised by lists of activities undertaken, together with a number of artefacts to show what they have done. There is likely to be little critical commentary explaining the evidence and linking it to their personal development. Those who are reflective individuals, who are asked to collect evidence of their achievements, are more likely to annotate their portfolio, perhaps providing un-solicited reflective comment.

Reflective students who are encouraged to consider their learning processes leading to an achievement are more likely to be critical and reflective. They are likely to produce work that shows evidence that they are aware of their own self-development. By contrast, when students who are not naturally inclined to reflect are encouraged to focus on learning processes, they may attempt to answer questions or prompts provided to them. However, this may become a 'tick-box' exercise, where students attempt to answer questions in a way that they believe will satisfy the assessor, rather than engaging in a deep, personal reflection. If no prompts are provided, then they may struggle to know what to write and the outcome may be a description of what they have done with little critical evaluation. In this case the student may provide excessive attention towards the presentation of the work, rather than the content. 




Figure 1 Model of the likely outcomes of reflective portfolios depending upon guidance given by tutors, and a student's propensity to reflect (Roberts, 2009, p.640)

One possible weakness of the model as it stands is that it is based on a premise that the focus of reflection is determined by guidance provided by teachers. The model does not account for situations where no such guidance is provided. In such a case would students naturally adopt a product or process focus?

\section{Methodology}

In order to test the validity of this model, it is necessary to classify the different approaches students take in writing their portfolios, particularly in terms of how they focus their reflection - whether in terms of product or process. This paper outlines the development of a rubric for the classification of portfolios which can be used in subsequent research to compare against student propensities to reflect. The majority of previous work in this area has been in the domains of education, health sciences and business and therefore there is a need to translate this existing work so that it appropriately addresses the nature of professional experience in the built environment field. The rubric would also need to be robust, with clearly defined categories that would allow a single researcher or indeed teacher to be able to categorise work with a reasonable degree of reliability.

The research uses as its source data a set of e-portfolios submitted by a cohort of 54 architecture students undertaking their first experience of professional practice in an architectural office. This experience occurred as part of a 'year out', between the students $3^{\text {rd }}$ and $5^{\text {th }}$ year studies. Whilst students are based in an office undertaking a range of professional work, they are required to complete an academic diet of assessed work and the 
e-portfolio forms a key element of this. In their e-portfolios students were asked to log their experience in terms of time spent on particular projects, set themselves goals for future development and conduct a regular series of critical reflections on their experience to date. It was these critical reflections that have been analysed in this paper.

At the start of the year, students are given basic guidance on what they might write in their critical evaluations in the form of a series of optional prompts that can help them reflect. The guidance suggests students consider what they regarded as challenging and why; their feelings, beliefs and assumptions and how these might have changed; the relationship between their experience and their initial expectations of practice; their roles and relationships to those of their colleagues; how they addressed the challenges encountered; the support and feedback they had and needed and what could be done better next time.

These prompts were designed to steer the students away from purely descriptive writing and to encourage something that is more reflective. Nevertheless, experience suggests that there will still be a broad range of levels and foci of reflection in the students' writing with many students simply ignoring the guidance. Experience also suggests that levels of reflection typically improve following the provision of formative feedback. For the purpose of this research, the scripts analysed were those written just before the first feedback was given so the students' writing would not be unduly influenced by the tutor's comments. These scripts were generally written between three and five months into the students' placements.

The portfolios are assessed at the end of the year, the principal criteria being the level of reflection undertaken by the students, rather than some measure of the work undertaken by the students This was measured using Bain et al.'s (1999) five point level of reflection scale. This scale was also used to provide the interim feedback to students.

The e-portfolios are stored on a password-protected university web server, and are accessible for the students to compare and contrast their experience with each other. Nevertheless, it is recognised that making the portfolios available to other students, and the fact that the portfolios will be assessed, is likely to compromise what students write, some shying away from exposing very personal aspects in their writing. This has to be weighed up against the benefits of peer assessment of students reviewing each other's work and the motivating impact of assessment (Creme, 2005).

The process of coding the scripts encompassed a number of iterations using NVIVO software. The first iteration involved reviewing a selected sample of three scripts from students whose writing was considered to be highly reflective, quite reflective and purely descriptive, in order to identify the potential foci of reflection. From this, three tentative foci emerged which were the consideration of the project or task the student had been working on (project focus), more general reflections on the practice that they had been working in (profession or practice focus), and reflections on their own personal development (personal development focus). These are outlined in Table 1. 
A. Roberts: Classifying the Nature of Reflective Writing During Periods of Professional Experience

Table1 Categories describing focus of reflection

Project Focus

Profession or Practice Focus

Personal Development Focus
Building or project context

Tasks undertaken and processes followed

Nature of practice (identity, context, market size)

Office/team processes (working relationships/support)

Feelings and emotions

What has been learned (knowledge, skills, expectations from university, new ways of thinking)

Nature of experience

Student's place within the practice (role, responsibilities, freedom, sense of worth, confidence, fitting in)

Student's learning process

The second iteration looked across all of the scripts and categorised each paragraph by these three foci, but also in terms of level of reflection. For simplicity, the level of reflection was categorised using a three point scale so that a low level of reflection would typically be a description with little reflection, a medium level of reflection would show the students making connections, for instance between theory and practice, and a high level would suggest some form of transformation in perspective. With the three foci, this lead to nine possible categories, with the definitions for each category refined during each subsequent iteration.

Paragraphs could be coded under more than one foci, and more than one level of reflection if necessary. For instance, in the following paragraph the student describes the project that she had worked on and how she contributed to that project. This was categorised as having a project focus at a low level of reflection. The student then goes on to explain what was learnt, and the process by which this learning had occurred. This was also categorised as having a personal development focus, but with a medium level of reflection.

"Much of the work I have done has been detailing. When I joined in September the scheme has just received planning permission and was ready to be detailed. I have been mainly drawing details in scales varying from 1:20 to 1:5. Not only has this really developed my understanding of construction, I am working with someone who knows a great deal and I have learnt a lot from just listening to him, it has shown how much really needs to go into the drawing."

At this stage, all categories, of both level and focus were held as provisional and could be amended during future iterations.

The third iteration then looked in more detail at the paragraphs within each of the nine categories. Each paragraph was checked for consistency in terms of level of reflection, and a series of sub categories were developed to categorise the type of things that would be written about under each of the different foci.

The final iteration involved the clustering of each of these sub categories into a small series of meta-headings. This led to the framework included in Appendix 1. 
A. Roberts: Classifying the Nature of Reflective Writing During Periods of Professional Experience

\section{Analysis of Results}

Generally the majority of the scripts analysed contained examples of Project, Professional and Personal foci. The majority contained examples of low and medium level reflection. Fewer students tended to reflect at a high level, and there was very little evidence of reflection that might be properly considered to be critical reflection (Table 2).

Table 2 Numbers of students with paragraphs coded in each category

\begin{tabular}{llll}
\hline \multicolumn{3}{l}{ Level of Reflection } & \\
\hline Focus of Reflection & High & Medium & Low \\
Project & $6(7)$ & $31(104)$ & $51(345)$ \\
Profession & $15(18)$ & $30(61)$ & $41(120)$ \\
Person & $13(24)$ & $44(216)$ & $43(205)$ \\
\hline
\end{tabular}

Total number of coded paragraphs shown in brackets

It also became apparent that what was classified as a low level of reflection within a project focus barely constituted reflection, and might be placed in the category of descriptive writing (Hatton and Smith, 1995). The lowest levels within the Personal and Professional focus did show some basic reflection as this would require them to provide some degree of reasoned justification or explanation on what had been described, which might fall under Hatton and Smith's description of Descriptive Reflection. Often in order to reflect on a professional situation, a student would need to generalise from the perspective provided by the individual task at hand. A basic consideration of a student's personal development might also require a degree of self-reflection and introspection, even if the outcome is little more than a student noting how they feel about a situation. This suggests that the level and focus of reflection are not entirely independent dimensions as suggested by LaBoskey (1993).

This has led to the generation of the model shown in Figure 2 which classifies the different types of writing encountered in terms of the level and focus of reflection. It uses Bain et al.'s (1999) scale as a point of reference against which to benchmark levels of reflection. The nature of each of the categories is summarised in the example extracts below. 


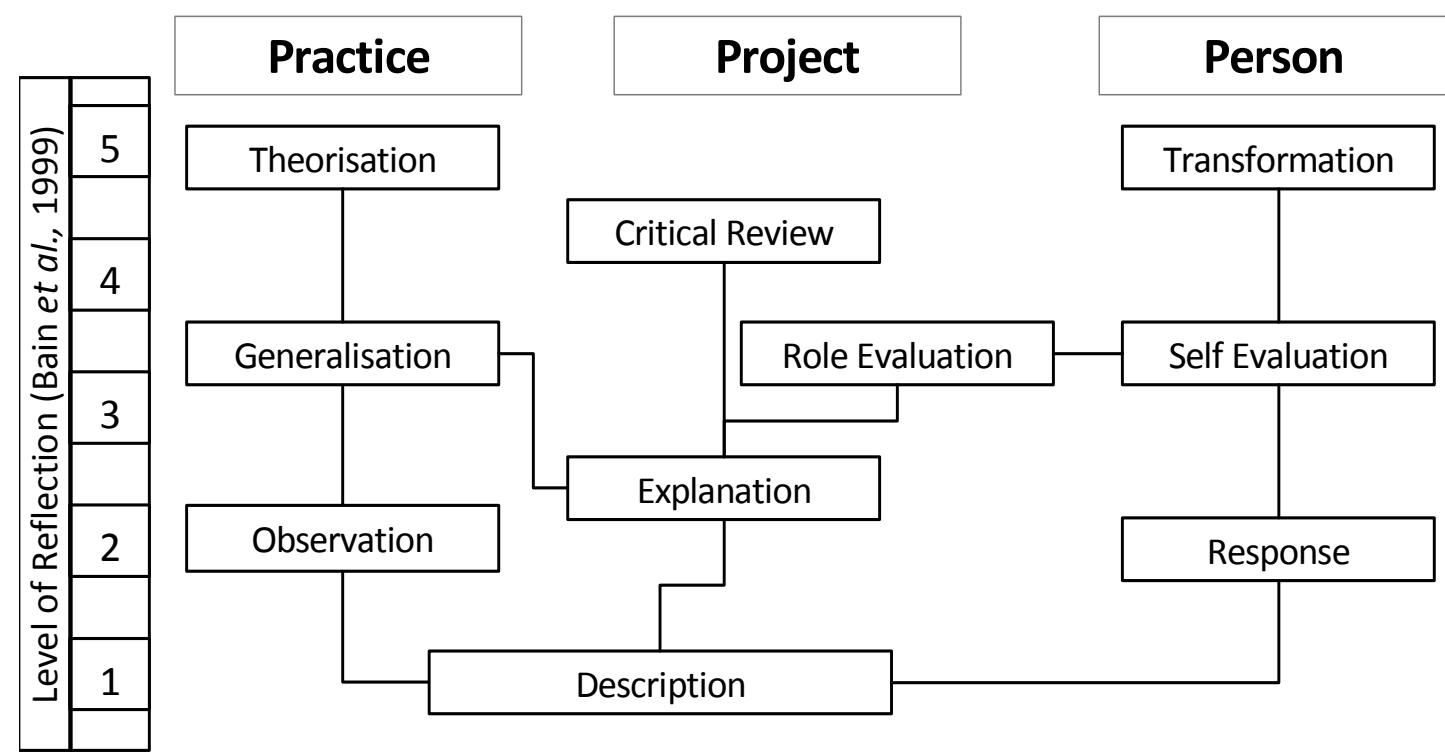

Key to Bain's Levels of reflection: 1 = reporting, 2 = responding, 3 = relating, 4 = reasoning, 5 = reconstructing

Figure 2 Categorisation of the type of writing provided by students, in terms of focus and level of reflection. Level of reflection based on scale by Bain et al. (1999).

In the case of many of the students studied, the starting point for most writing is a description of the project on which they were working, and any specific tasks that they were required to undertake. As most work in architectural practices is project based, this type of description was ubiquitous amongst all students. Some may also provide a general description of the office environment within which they are working, for instance in terms of the number of members of staff present and the type of work typically carried out by their firm. At the lowest level, some students may stop at this point, barely demonstrating any degree of reflection. Those who do continue may do this in three possible directions related to the three foci of reflection mentioned earlier. Some may go on to explain the project in terms of its context or their engagement with it, although there may be little transformation or conceptualisation. This level has been labelled Explanation in Figure 2 and is typified by the following quotes. The first focuses on the building that the student has been working on and provides some historical context, the second focuses on the task or challenge being undertaken and the third explains how the student interacted with others in order to complete a task. Readers should note that all quotations shown below are as taken directly from the student scripts with grammar and punctuation remaining uncorrected.

"The project involves an existing timber frame building. This was then dismantled in about $1865 \ldots$ and placed in a Grange near the centre of town. It was bought by a solicitor who converted it into a house and has obviously been extended many times. Therefore giving a building which has amazing heritage in the original core but the extensions create a building with many levels and fragmented rooms." 
A. Roberts: Classifying the Nature of Reflective Writing During Periods of Professional Experience

"I have also been involved in designing the section of the building and positioning of the windows in relation to how the interior is used as well as the proportions in the exterior facade. This was an exercise in trying various options and reaching a compromise between different desired qualities."

“... asked me to produce a sketch-up model for the client so he could show her his initial ideas for the scheme in 3D form. ... [he] had a vague idea of how it might work in greater detail but had nothing finalised so once he saw the model and gained a greater understanding of the spaces he got me to tweak the model. He'd usually give me a few options which I would model and then he'd come back and we'd have a group discussion about which ones work with all three of us involved."

These explanations tend to fall somewhere between level 2 (responding) and level 3 (relating) in Bain et al.'s scale. They also tend to be very external in nature, ignoring their personal reaction to the circumstances. If the student remains totally focussed on the project that they are working on, then the highest possible level they will reach is likely to be a critical review of the project as suggested below.

"...the idea works well in model, but in onsite the building does not feel tied into the earth at all currently. It feels like a rock above the river. Not fragile and delicate, but protective of its contents - very good considering its purpose of protecting the river. Perhaps there could have been a better way to draw the extrusions of these piles upwards and reveal them more from the exterior of the design."

Alternatively others may take their explanation further by evaluating their role at a more critical level, perhaps in terms of how they relate to other people in the office (Role Evaluation), or by suggesting strengths, weaknesses and how they might improve, which might in turn become more personal reflection on what they have learned (Self Evaluation). This would demonstrate a personal development focus as suggested by the following quotation.

"Recently, I have had the opportunity to participate in most of the Tender and Pre contract meetings prior to construction. With the return of several tenders, it has now become a cost cutting exercise bringing together all consultants to see where items can be reduced or even taken out of the schedule. I felt at times during the meetings I did not have the confidence or authority to engage in the discussions due to my lack of experience, however, I have voiced my opinions regarding an alternative staircase construction but this was not carried through. Although participation on my behalf has been quite limited it has been a fascinating process to be involved in."

Others may reflect on their project in a way that allows them to generalise their experience to wider aspects of professional life (Generalisation) which also suggests a focus on the profession or practice. The following quotation highlights this.

"Despite the obvious disappointment of standing down on the project, I felt this experience was the most useful of my time in practice to date. It demonstrated the importance of accountability in record keeping, so that there is evidence to support the payment of fees, when a client threatens to withhold them. An unfavourable 
A. Roberts: Classifying the Nature of Reflective Writing During Periods of Professional Experience

economic climate can force a practice to take on work/a client that they previously wouldn't have considered, and its seems that under these circumstances it is even more important to be fully accountable and do as little work beyond your fees as possible."

On other occasions, students might move from a pure description of their work, onto making some more general observations of the architectural practice and general office processes; they may also make a judgement or express an opinion, but at a lowest level, this may not offer any sophistication in terms of suggesting reasons why things are as they are beyond that which perhaps they have been told by colleagues (Observation). For instance:

"The partners, ... established the practice in ... and have built up a portfolio mostly in the historical conservation field, in which they both have extensive experience. The majority of their work is focused on historical buildings, churches and interventions into an existing fabric; requiring a sensitive and responsible design approach."

Students who take this further will start to generalise specific observations from their project into a personal theory or hypothesis. In some cases this might be a superficial explanation, but in others it may involve a greater degree of sophistication, based on a broad range of personal insights, experiences and previous learning (Generalisation) as highlighted by the following quotes. These would fall somewhere between levels 3 and 4 in Bain et al.'s (1999) scale.

"Something else I have learnt is to realise that in architecture practices lots of mistakes, and quite often very costly ones, are made, and I cannot take for granted that someone else's or my own work will be accurate. I have learnt to be diligent and check all work that I contribute."

"Working in small teams creates more respect and communication within the office environment whilst keeping productivity and moral higher than it would be if each member of the small team worked individually."

At best students may show a high level of abstract thinking, drawing original conclusions and building a new theory from their observations and experiences (Theorisation), although there was little evidence of thinking at this level in the cohort analysed.

If reflection takes on a personal focus, then students will make some initial response to the task that they have described. They may express a feeling or emotion, or they may conduct a largely superficial listing of the things that they have learned or what they need to learn (Response). The first quote below suggests the student expressing emotions, whist the second shows the student simply listing what has been learned. The third lists what the student thinks needs to be learned or done, but this is often based on a superficial desire to gain as wide an experience as possible, rather than a deep consideration of the student's immediate learning needs. These are unlikely to go above level 2 in Bain et al.'s (1999) reflection scale. 
A. Roberts: Classifying the Nature of Reflective Writing During Periods of Professional Experience

"Joining the [location] Primary team I started to feel like I was doing the work that I thought I would be doing as an architect. While much of the work and the tasks given to me were new, I felt apprehensive and also excited by the challenge of the work."

"I have enjoyed working on a range of different projects at the same time as the challenges have been diverse - learning how to survey, submit planning applications and continue to make detail design drawings. However it also introduced the challenge of balancing the workload and ensuring nothing was forgotten."

"I do feel that I need variation in different tasks and of different work stages to gain a wider experience of practice. Attending client meetings and site experience is vital but not yet achieved."

On other occasions students may support these statements with a greater degree of selfreflection, considering in greater depth what (and how) they had learned and what they need to improve. At this level they might also contextualise their learning in terms of their prior knowledge and suggest strategies for further improvement (Self-Evaluation). The first quotation below suggests a greater evaluation of the skills that had been acquired and how confidence had developed. In the second quote the student compares her learning with what was learned at university. In the third, the student highlights how she might have improved her performance. This self-evaluation typically falls between levels 3 and 4 in Bain et al.'s (1999) scale.

"I found myself being able to answer questions that I would have not been previously been able to and questioning contractor's queries, rather than just assuming the contractor was correct. I now feel more confident to take on larger tasks. Taking on this larger amount of responsibility meant that I began having more discussions with the contractor, acoustic consultants and M\&E consultants and began to feel more like a member of the team."

"I picked up things in the office that one would not be taught at university, such as the politics involved in getting and keeping a project, the disputes which occur within the design team due to lack of communication and also lack of respect between team members. I was startling to notice the amount of 'buck-passing' and poor team work that goes on between architects, engineers and contractors."

"To improve my performance on this particular task I would have tried harder to contribute my own ideas and offer critiques of the new build design options. I was involved in several discussions, however due to lack of confidence and my unfamiliarity to such situations I did not voice my opinions. I believe that I would have learned more through offering my opinion and listening to my colleagues' subsequent reactions, I may have also gained some respect as a valuable member of the team had my opinions been valid."

At the highest level students might realise that a qualitative transformation in perspective had occurred, and that they see the world in a different way as a result of their experience (Transformation). The following quotes suggest that students are seeing architectural practice in a different way as a result of their experience. 
A. Roberts: Classifying the Nature of Reflective Writing During Periods of Professional Experience

"I was quite shocked to see how far the project had come and also how I had almost forgotten that it was on site. This project has really opened my eyes to other roles in a design team and the issues other team members may have. It has also really influenced how I think about detail design drawings, what information is important and what is absolutely key to contractor to help them understand the scope of the design and to cost the project successfully."

"Another key personal development has been in my approach to design. I genuinely feel that I will have a much more mature approach to my own work having experienced the process in an architecture firm. Previously, I had the tendency to get too hung up on little details of an idea, rather than define the overall concept. I also often found myself giving up on ideas because I ran into problems with them at the very early stages of the project. However I now realise that it is better to concentrate on the overall uniting concept of a project at the early stages."

These quotations clearly show a range of different approaches to reflection. This has been summarised in the rubric in Appendix 1.

It was clear from the analysis that certain students were placing a greater emphasis on the personal development and performance aspects of reflection, whilst others placed a greater emphasis on learning and contextualising their experience. The question remains as to whether there is some reason why different students adopt a different focus. It is possible that this is a result of the context within which they are working, the nature of their experience, or it could be the result of some individual difference within the students as suggested earlier in the paper. The results here suggest that propensity to reflect might not only impact upon students' level of reflection, but also on the focus of reflection they are inclined to adopt. This range of foci appeared not to have been limited by the guidance the students were given when writing their portfolios.

At the start of this paper it was suggested that the different forms of reflection would occur depending upon the goals that are set by both staff and students (Moon, 1999). The data analysed above has highlighted two different goals being followed by the students, perhaps requiring very different mental processes. The first goal is a desire to understand the subject, in this case the professional practice of architecture. With this goal, the emphasis would be on making connections between their professional experience and their pre-conceptions and theories that may have been previously dealt with in academic situations. In this case reflection becomes a tool by which theory can be contextualised, the ultimate outcome being an 'upgrade' of the students' learning (Moon, 1999, p.154). Students may reach high (transformative) levels of reflection if they critically question some of these relationships. In the case of this research, students who focussed their reflection on Project or Practice issues are likely to have adopted this goal, although it is unlikely that transformative levels of reflection would be reached without students adopting a personal perspective, for instance by questioning their assumptions and beliefs. The subject of reflection here is usually external to the student. 
The second goal would be for the students to use reflection to improve their performance in practice related tasks. This might, for instance, require the students to think about what they might do differently next time. It would require them to question the relationships that they might have with colleagues, and how they manage office processes. Typically these students would focus on their own personal development and from the sample illustrated in this research, this tended not to lead to a transformation in perspective with the majority of the students. For this to happen, students would need to question critically their own attitudes towards the task in hand. In this case the subject of reflection is internal to the student.

It is worth noting that in other disciplines, such as health and education, the development of students as reflective practitioners is commonly seen as a goal in itself. This is perhaps taking a longer-term view developing students' capabilities to reflect in future situations of uncertainty, without the guidance of academic staff. It would be wrong to suggest that this was not an overall aim of the staff supporting the work described in this paper, but perhaps it is something that is less explicit in the guidance and documentation given to students. This is an area that takes time to evolve, particularly as students need to develop a reasonable understanding of the routine activities and contexts within which they are working before they can develop into reflective practitioners (Hatton and Smith, 1995). To identify the impact of this on student portfolios and on their subsequent learning, would require a longer, more detailed study.

\section{Conclusion}

Whilst the research outlined here is based on a sample of architecture students, its findings are likely to be relevant elsewhere. The findings highlight the broad range of forms that reflection might take and it was clear that certain students were placing a greater emphasis on different aspects of reflection. The reasons for these differences are unclear, but may be a result of the individual differences highlighted at the start of this paper or the goals set by students and staff. It is possible that students with a high propensity towards self-reflection might be more likely to engage in reflection with a personal development focus. This is the subject of on-going research. The findings of this paper also raise questions about the notions of product and process as the two principal foci of reflection highlighted in the model in the paper's introduction. It is suggested that reflection is likely to be either internally focussed (personal development) or externally focussed (learning about practice).

The principal outcome of this study is the development of a classification system by which the content of portfolios can be assessed in terms of both level and focus of reflection. By codifying what might typically appear in a portfolio, it becomes possible to classify objectively individual pieces of writing. This would be necessary in order to address further questions as to why certain students adopt different approaches to their portfolio writing. Beyond its use as a research tool, the classification also has practical benefits in teaching and can be used as a means to give feedback to students on their portfolio writing, and possibly as a tool used by students to encourage reflection on what they have written within their portfolios. 
A. Roberts: Classifying the Nature of Reflective Writing During Periods of Professional Experience

\section{References}

Bain, J. D., Ballantyne, R., Packer, J. \& Mills, C. (1999). Using journal writing to enhance student teachers' reflectivity during field experience placements. Teachers and Teaching, 5 (1), 51-73.

Biggs, J. B. \& Tang, C. S. (2007). Teaching for quality learning at university: What the student does. 3rd ed. Maidenhead: Open University Press.

Blackwell, A., Bowes, L., Harvey, L., Hesketh, A. J. \& Knight, P. T. (2001). Transforming work experience in higher education. British Educational Research Journal, 27 (3), 269-285.

Boud, D., Keogh, R. \& Walker, D. (1985). Reflection: Turning experience into learning. London: Kogan Page.

Calderhead, J. (1988). Teachers' professional learning. London: Falmer.

Cranton, P. (2006). Understanding and promoting transformative learning: A guide for educators of adults. 2nd ed. San Francisco, Calif.: Jossey-Bass.

Creme, P. (2005). Should student learning journals be assessed? Assessment \& Evaluation in Higher Education, 30 (3), 287-296.

Dewey, J. (1933). How we think: A restatement of the relation of reflective thinking to the educative process. Boston, Mass.: Heath.

Grant, A. M., Franklin, J. \& Langford, P. (2002). The self-reflection and insight scale: A new measure of private self-consciousness. Social Behavior and Personality, 30 (8), 821-835.

Habermas, J. (1987). Knowledge and human interests. Cambridge: Polity Press.

Hatton, N. \& Smith, D. (1995). Reflection in teacher education: Towards definition and implementation. Teaching and Teacher Education, 11 (1), 33-49.

Kagan, J., Rosman, B. L., Day, D., Albert, J. \& Phillips, W. (1964). Information-processing in the child - significance of analytic and reflective attitudes. Psychological Monographs, 78 (1), 1-37.

Kember, D., Jones, A., Loke, A., Mckay, J., Sinclair, K., Tse, H. \& Yeung, E., Webb, C., Wong, F. \& Wong, M. (1999). Determining the level of reflective thinking from students' written journals using a coding scheme based on the work of Mezirow. International Journal of Lifelong Education, 18 (1), 18-30.

Kolb, D. A. (1984). Experiential learning: Experience as the source of learning and development. Englewood Cliffs; London: Prentice-Hall.

LaBoskey, V. K. (1993). A conceptual framework for reflection in preservice teacher education. In: Calderhead, J. \& Gates, P. (Eds.). Conceptualizing reflection in teacher development. London: Washington Falmer Press, pp. 23-38.

McCarthy, J. (2011). Reflective writing, higher education and professional practice. Journal for Education in the Built Environment, 6 (1), 29-43. 
A. Roberts: Classifying the Nature of Reflective Writing During Periods of Professional Experience

Mezirow, J. (1991). Transformative dimensions of adult learning. 1st ed. San Francisco: Jossey-Bass.

Moon, J. A. (1999). Reflection in learning and professional development: Theory and practice. London: Kogan Page.

Platzer, H., Snelling, J. \& Blake, D. (1997). Promoting reflective practitioners in nursing: A review of theoretical models and research into the use of diaries and journals to facilitate reflection. Teaching in Higher Education, 2 (2), 103-121.

Roberts, A. (2009). Encouraging reflective practice in periods of professional workplace experience: The development of a conceptual model. Reflective Practice, 10 (5), 633-644.

Roberts, A. \& Yoell, H. (2009). Reflectors, converts and the disengaged: A study of undergraduate architecture students' perceptions of undertaking learning journals. Journal for Education in the Built Environment, 4 (2), 74-93.

Samuels, M, \& Betts, J. (2007). Crossing the threshold from description to deconstruction and reconstruction: Using self-assessment to deepen reflection. Reflective Practice, 8 (2), 269-283.

Schön, D. A. (1983). The reflective practitioner: How professionals think in action. London: Temple Smith.

Smith, K. \& Tillema, H. (2003). Clarifying different types of portfolio use. Assessment \& Evaluation in Higher Education, 28 (6), 625-648. 
Appendix 1: Summary of the nature of students' writing in the nine categories of level and focus of reflection. A rubric for assessment

\begin{tabular}{|c|c|c|c|}
\hline & High Reflection & Medium Reflection & Low Reflection \\
\hline \multirow[t]{5}{*}{ Project Focus } & Critical Review & Explanation & Description \\
\hline & $\begin{array}{l}\text { Provides a critical review of the building or } \\
\text { project. }\end{array}$ & \multirow{2}{*}{$\begin{array}{l}\text { Provides information about the project, but } \\
\text { makes links to the reasons why things are as } \\
\text { they are. }\end{array}$} & $\begin{array}{l}\text { Describes aspects of project, for instance } \\
\text { client requirements, schedules etc. }\end{array}$ \\
\hline & Role Evaluation & & Outlines what they have done. \\
\hline & \multirow[t]{2}{*}{$\begin{array}{l}\text { Students evaluate their contribution towards the } \\
\text { project. }\end{array}$} & $\begin{array}{l}\text { Outlines what they have found challenging } \\
\text { and why. }\end{array}$ & \multirow[t]{2}{*}{$\begin{array}{l}\text { Outlines how things were done on the project } \\
\text { (not necessarily what they did). }\end{array}$} \\
\hline & & $\begin{array}{l}\text { Outlines how they contributed towards the } \\
\text { project and interacted with others. }\end{array}$ & \\
\hline \multirow{4}{*}{$\begin{array}{l}\text { Profession or } \\
\text { Practice } \\
\text { Focus }\end{array}$} & Theorisation & Generalisation & Observation \\
\hline & $\begin{array}{l}\text { Proposes some novel theory about how practices } \\
\text { work. }\end{array}$ & \multirow{3}{*}{$\begin{array}{l}\text { Generalises observations within their } \\
\text { practice to wider practice. Makes } \\
\text { comparison with other prior experience. }\end{array}$} & $\begin{array}{l}\text { Observes nature of individual's practice/office. } \\
\text { Describes context. }\end{array}$ \\
\hline & Critically evaluates process. & & Describes process observed within practice. \\
\hline & $\begin{array}{l}\text { Improves process. Expresses an opinion on } \\
\text { success or failure, and gives reasoning. }\end{array}$ & & \\
\hline \multirow{7}{*}{$\begin{array}{l}\text { Personal } \\
\text { Development } \\
\text { focus }\end{array}$} & Transformation & Self Evaluation & Response \\
\hline & Highlights new insights. & Reflects on how they have developed. & \multirow{2}{*}{$\begin{array}{l}\text { Expresses a simple emotion (like, dislike). } \\
\text { Describes difficulty encountered, a } \\
\text { challenging task. }\end{array}$} \\
\hline & Evaluates success in meeting challenges. & Shows emotions - but explains why these & \\
\hline & $\begin{array}{l}\text { Sees their experience in a new way. } \\
\text { Overall evaluation of impact of placement, very }\end{array}$ & $\begin{array}{l}\text { Explains how they have improved. Extracts } \\
\text { skills rather than broad aspects. }\end{array}$ & $\begin{array}{l}\text { Lists what has been learned or needs to have } \\
\text { been learned. }\end{array}$ \\
\hline & \multirow{3}{*}{$\begin{array}{l}\text { Shows high degree of introspection in terms of } \\
\text { understanding how they learn. }\end{array}$} & Links practice and theory. & \multirow{3}{*}{$\begin{array}{l}\text { Lists things they need to do based on } \\
\text { standard pre-conception, range of experience } \\
\text { within plan of work etc. }\end{array}$} \\
\hline & & $\begin{array}{l}\text { Evaluates benefit of experience and } \\
\text { highlights carefully areas for improvement. } \\
\text { What would they do better next time? } \\
\text { Generally project/task specific. }\end{array}$ & \\
\hline & & Outlines what has helped them to learn. & \\
\hline
\end{tabular}

